\title{
“Dexmedetomidine V/S Fentanyl with 0.75\% Ropivacaine for Epidural Anaesthesia in Lower Abdominal Surgeries - A Comparative Study"
}

\author{
Pratibha Jain Shah ${ }^{1}$, Rashmi Naik ${ }^{2}$, Chandrapal Bhagat ${ }^{3}$, Kunal Talreja ${ }^{4 *}$ \\ ${ }^{1}$ Professor and Head, Department of Anaesthesiology and Critical care, Pt. Jawahar Lal Nehru Memorial Medical College, India \\ ${ }^{2}$ Associate Professor, Department of Anaesthesiology and Critical care, Pt. Jawahar Lal Nehru Memorial Medical College, India \\ ${ }^{3}$ Assistant Professor, Department of Anaesthesiology and Critical care, Pt. Jawahar Lal Nehru Memorial Medical College, India \\ ${ }^{4} \mathrm{PG}$ resident $3^{\text {rd }}$ year, Department of Anaesthesiology and Critical care, Pt. Jawahar Lal Nehru Memorial Medical College, India
}

Submission: June 05, 2017; Published: July 12, 2017

*Corresponding author: Kunal Talreja, PG resident $3^{\text {rd }}$ year, Department of Anaesthesiology and Critical care, Pt. Jawahar Lal Nehru Memorial Medical College, India, Email: oxygen758@gmail.com

\begin{abstract}
Background: Opioids as epidural adjunct to local anaesthetics have been in use since long and $\alpha-2$ agonists are being increasingly used for similar purpose. This study was done to compare the effects of epidurally administered dexmedetomidine and fentanyl in combination with Ropivacaine $0.75 \%$ in lower abdominal surgeries.
\end{abstract}

Methods: 80 patients of either sex, aged 18-55 years, ASA grade I-II posted for elective lower abdominal surgery were divided into two groups $(\mathrm{n}=40)$ by open label randomization chit method. Group RD received $1 \mu \mathrm{g} / \mathrm{kg}$ Dexmedetomidine and group RF received $1 \mu \mathrm{g} / \mathrm{kg}$ Fentanyl along with $15 \mathrm{ml}$ Ropivacaine $0.75 \%$. Onset and time of complete sensory and motor blockade, two segmental dermatomal regression, duration of analgesia, first 24 hour total LA consumption and complications were recorded. Data were compiled and analysed using Chi-square test and Fisher's exact test.

Results: Onset of complete sensory and motor block was significantly earlier in the $\operatorname{RD}(9.375 \pm 0.2256 \mathrm{~min}$ and $14.65 \pm 0.3588 \mathrm{~min})$ as compared to group $\mathrm{RF}(11.45 \pm 0.3281 \mathrm{~min}$ and $17.1 \pm 0.4294 \mathrm{~min})(\mathbf{p}<\mathbf{0 . 0 0 0 1})$. Postoperative analgesia was significantly prolonged in group $\mathrm{RD}$ as compared to group RF $(374.3 \pm 6.793 \mathrm{Vs} 283.5 \pm 5.576 \mathrm{~min})(\mathbf{p}<\mathbf{0 . 0 0 0 1})$.Total duration of motor and sensory block was longer in group RD (276.6 \pm 5.668 and $140.9 \pm 3.602 \mathrm{~min}$ ) as compared to group $\mathrm{RF}(198.4 \pm 4.509$ and $117.8 \pm 2.715 \mathrm{~min})(\mathbf{p}<\mathbf{0 . 0 0 0 1})$. Total LA consumption was lesser in group RD as compared to group RF $(112.5 \pm 7.869 \mathrm{mgVs} 132.5 \pm 8.758 \mathrm{mg})(\mathbf{p}<\mathbf{0 . 0 0 0 1})$. Hypotension, bradycardia and dry mouth was significant in group RD while nausea and vomiting was significant in group RF.

Conclusion: Dexmedetomidine is better alternative to fentanyl as an epidural adjuvant, due to comparatively faster onset of blockade, prolonged postoperative analgesia and lower consumption of post-op LA.

Keywords: Dexmedetomidine; Fentanyl; Epidural anaesthesia

\section{Introduction}

Epidural anaesthesia is an integral part of today's practice of anaesthesia, as it gives the anaesthesiologist the opportunity to place it at any level of the vertebrae to provide anaesthesia and analgesia, to supplement general anaesthesia, decrease the need for deep levels of general anaesthesia and therefore provide haemodynamically stable operative course. As early postoperative mobilization and rehabilitation with minimally associated pain and discomfort is the most desirable feature for modern orthopaedic and general surgeries so epidural becomes desirable technique of anaesthesia [1]. It not only provides perioperative surgical anaesthesia but also post-op analgesia in lower abdominal and limb surgeries [2].

Epidural bupivacaine was used since long but it is highly cardiotoxic. Recently ropivacaine became better alternative in choice of LA, due to long duration and less cardiovascular effects [3]. Very slow reversal of $\mathrm{Na}^{+}$channel blockade after a cardiac action potential, which is the hallmark of bupivacaine, is considerably faster with ropivacaine, also the negative inotropic 
potency of ropivacaine on isolated cardiac tissue appears to be considerably less than that of bupivaicaine [4]. Adding adjuvants to LA have proven better and faster onset of blockade, prolonged duration of action and postoperative analgesia with lower consumption of local anaesthetic. Adjuvants like opioids can perform these activities but as to their certain side effects like pruritus, urinary retention, nausea and vomiting, newer adjuvants are been considered.

Fentanyl, a highly lipophilic opioid, has relatively rapid onset of action following administration. It has become very popular additive in recent times. However, it has side effects like pruritus, nausea and vomiting, hence, there was need for an alternative which was deprived of these side effects but has same or better qualities like opioids when used as adjuvant.

Dexmedetomidine is a new addition of $\alpha-2$ agonist which has got numerous beneficial effects when used through epidural route. It does cause manageable hypotension and bradycardia but the striking effect of it is lack of opioid related side effects. Because of paucity of comparative studies between fentanyl and dexmedetomidine as an adjuvant to ropivacaine for epidural anaesthesia, we decided to compare both these drugs in our institute in terms ofonset and time of complete sensory and motor blockade, two segmental dermatomal regression, duration of analgesia, first 24 hour total LA consumption and complications.

\section{Method}

Present study was conducted in the Department of Anaesthesiology and Critical care, Pt. J.N.M. Medical College and Dr. B.R.A.M. Hospital Raipur (C.G) after approval from the institutional ethics committee. It was a prospective randomizeddouble blind study, 80 patients of ASA I-Ilaged 18-55 years of either sex undergoing lower abdominal surgeries were randomly allocated by chit method into 2 Groups (n=40). Group $\mathrm{RD}$ received dexmedetomidine $1 \mu \mathrm{g} / \mathrm{kg}$ and Group $\mathrm{RF}$ received fentanyl $1 \mu \mathrm{g} / \mathrm{kg}$ along with ropivacaine $0.75 \% 15 \mathrm{ml}$. Before the study, power of study was calculated by using software $G$ power 3.0.10, taking mean value for onset of sensory blockade from Bajwa S, et al. [5] and considering a probability level of 0.05 ( $\alpha$-error) and power of $0.80(1-\beta)$ yielded a sample size of 40 patients in each group.

Patients with history of drug allergy, gross spinal abnormality, localized skin sepsis, hemorrhagic diathesis, neurological disease, hepatic and renal diseases, peripheral neuropathy and psychiatric diseases were excluded from the study.

After preoperative assessment, written informed consent was taken from all patient and kept nil orally for 8 hrs before surgery. On the day of surgery, intravenous line was secured and preloaded with Ringer Lactate solution $10 \mathrm{ml} / \mathrm{kg}$ over 20 minutes prior to the procedure, all patients were premedicated with i.v. 50 mg Ranitidine and i.v. Ondensatron $4 \mathrm{mg} 15 \mathrm{~min}$ prior to epidural anaesthesia.
Epidural anaesthesia was performed in sitting position and under all aseptic precautions, L3-L4 or L2-L3 interspace was identified and local infiltration by $2 \mathrm{ml} 2 \%$ lignocaine with adrenaline was done at one of the interspaces. An epidural needle (Tuohy's) 18G was inserted through the midline approach and epidural space was located by loss of resistance to air method. Direction of the bevel was kept cephalad in all the cases. A disposable sterile multi hole epidural catheter was threaded 3-5 $\mathrm{cm}$ cephalad in the epidural space and was secured with adhesive tape. Test dose of $3 \mathrm{ml} \mathrm{2 \%}$ lignocaine with adrenaline 1:200000 was injected, followed by total volume of $15 \mathrm{ml}$ of either of the study drug were injected through the epidural catheter.Epidural supplementation was done on requirement of analgesia in postoperative period by $0.2 \%$ ropivacaine $10 \mathrm{ml}$.

Sensory block was assessed by pin prick method at every 2 min interval till $30 \mathrm{~min}$ and then every $15 \mathrm{~min}$ until the return of normal sensation at dermatome levels $\mathrm{S}_{3}, \mathrm{~S}_{1}, \mathrm{~L}_{5}, \mathrm{~L}_{3}, \mathrm{~L}_{1}, \mathrm{~T}_{12}, \mathrm{~T}_{10}, \mathrm{~T}_{8}$ and $\mathrm{T}_{6}$ and the maximal sensory blockade level was noted. Onset and end of all degrees of motor blocks were assessed bilaterally according to the Modified Bromage scale [6] until the return of Bromage 1. [ $0=$ No motor block (ability to move hips, knees and ankles), 1 = inability to raise extended leg (able to flex knee); 2 = inability to flex knee (able to flex foot only); 3 = inability to flex ankle joint (unable to flex foot or knee)].

Onset of sensory blockade (time interval from epidural injection of drugs to sensory blockade at T10), onset of motor block (time interval from epidural injection of drug to achieve modified Bromage scale grade I), extent of block (highest dermatomal level of sensory block achieved), duration of sensory block (time to two segmental dermatome regression), duration of motor block (time interval fromachievement of Bromage I to regression of motor blockade to Bromage I), duration of analgesia (time from onset of sensory block to first complain of pain), sedation score was observed and recorded. Hemodynamic parameters like $\mathrm{PR}, \mathrm{SBP}, \mathrm{DBP}, \mathrm{MBP}, \mathrm{RR}$, and $\mathrm{SpO}_{2}$ were recorded before induction and at every 5 minutes intervals for 30 minutes and later at 15 minutes intervals lasting for the entire duration of surgery.

Sedation score5was assessed by Ramsay Sedation Score and recorded just before the initiation of surgery and thereafter every 20 minutes during the surgical procedure (1-alert and wide awake, 2-arousable to verbal command, 3-arousable with gentle tactile stimulation, 4-arousable with vigorous shaking, 5-unarousable). Total dose consumption of local anaesthetic over 24 hours (total dose required till 24 hours including surgery and post-operative period) was recorded.

Fall in SBP and DBP $\geq 20 \%$ of baseline was considered as significant hypotension. It was managed with fast fluid administration and i.v. mephentermine 6 mg. Heart rate <50/ min was considered as bradycardia and treated with atropine $0.5 \mathrm{mg}$ i.v. Supplement $\mathrm{O}_{2}$ via face mask was given when $\mathrm{SpO}_{2}$ 
fell below 95\%. Nausea and vomiting was treated with inj. metaclopramide $10 \mathrm{mg}$.

Throughout the procedure, patients were observed for any side effects and complications related to technique and anaesthetics drugs by lumber epidural anaesthesia and recorded. Statistical analysis was done using Graph pad prism 7 Software. Data were analyzed by student $t$ unpaired test and chi square test. The results were analyzed by various statistical techniques like percentage, mean and standard deviation. P-value $<0.05$ was considered significant and $p$-value $<0.0001$ was considered highly significant.

\section{Result}

The two groups were statistically comparable with regard to demographic data (Table 1). Onset of sensory and motor blockade in group RD was significantly faster as compared to group $\mathrm{RF}$, andthe difference was statistically highly significant $(\mathrm{p}<0.0001)$ (Table 2).

Table 1: Demographic Data.

\begin{tabular}{|c|c|c|c|}
\hline $\begin{array}{c}\text { Demographic } \\
\text { Variables }\end{array}$ & $\begin{array}{c}\text { Group RD } \\
\text { (Mean } \pm \text { SD) }\end{array}$ & $\begin{array}{c}\text { Group RF } \\
\text { (Mean } \pm \text { SD) }\end{array}$ & P Value \\
\hline Age (Years) & $41.93 \pm 1.587$ & $39.55 \pm 1.735$ & $\mathrm{p}>0.05$ \\
\hline Weight $(\mathrm{kg})$ & $45.88 \pm 0.8135$ & $47.0 \pm 0.8697$ & $\mathrm{p}>0.05$ \\
\hline Height $(\mathrm{cm})$ & $152.2 \pm 0.262$ & $151.7 \pm 0.2679$ & $\mathrm{p}>0.05$ \\
\hline Sex $(\mathrm{M}: \mathrm{F})$ & $38: 02$ & $39: 01$ & $\mathrm{p}>0.05$ \\
\hline
\end{tabular}

The highestlevel of sensory block achieved was T5-T6 level in group RD which was higher than group RF i.e. T6-T7 level. The number of patients who achieved grade III and grade II motor blockade was 36 and 04 in group RD as compared to 34 and 06 in Group RF. This difference between both the groups proved higher level of block was achieved in group RD compared to group RF.

Table 2: Sensory and Motor block characteristic.

\begin{tabular}{|c|c|c|c|}
\hline Variables & Group RD & Group RF & p Value \\
\hline Onset of sensory blockade at & $9.375 \pm$ & $11.45 \pm$ & \\
$\mathrm{T}_{10}$ level (min) & 0.2256 & 0.3281 & $<0.0001$ \\
\hline \multirow{2}{*}{ Onset of motor blockade (min) } & $14.65 \pm$ & $17.1 \pm$ & $<0.0001$ \\
& 0.3588 & 0.4294 & \\
\hline Time to two segmental & $140.9 \pm$ & $117.8 \pm$ & $<0.0001$ \\
regression (min) & 3.602 & 2.715 & \\
\hline Time to regression to bromage & $276.6 \pm$ & $198.4 \pm$ & $<0.0001$ \\
\hline 1 (min) & 5688 & 4.509 & \\
\hline Total duration of analgesia in & $374.3 \pm$ & $283.5 \pm$ & $<0.0001$ \\
two groups (min) & 6.793 & 5.576 & \\
\hline
\end{tabular}

Duration of sensory blockwas significantly prolonged in group RDas compared to group RF, and the difference was statistically highly significant $(\mathrm{p}<0.0001)$ (Table 2$)$. Duration of motor blockade and duration of analgesia was also significantly prolonged in group $\mathrm{RD}$ as compared to group $\mathrm{RF}$, and the difference was statistically highly significant $(\mathrm{p}<0.0001)$ (Table 2). Total LA dose consumption over first 24 hours was $112.5 \pm$
$7.869 \mathrm{mg}$ in group RD and $132.5 \pm 8.758$ mgin group RF. This was significantly low in RD group $(\mathbf{p}<\mathbf{0 . 0 0 0 1})$.

Maximum number of patients in both groups had grade II sedation score i.e. 20(50\%) in Group RD and 22 (55\%) in Group RF. Higher number of patients in Group RD had grade III of Ramsay Sedation Score i.e. 14 (35\%) as compared to 02 (05\%) in Group RF (Table 3).

\section{Table 3: Sedation Score.}

\begin{tabular}{|c|c|c|c|}
\hline S. No & Sedation Score & RD (\%) & RF (\%) \\
\hline 1 & GRADE I & $06(15 \%)$ & $16(40 \%)$ \\
\hline 2 & GRADE II & $20(50 \%)$ & $22(55 \%)$ \\
\hline 3 & GRADE III & $14(35 \%)$ & $02(05 \%)$ \\
\hline 4 & GRADE IV & $0(0 \%)$ & $0(0 \%)$ \\
\hline 5 & GRADE V & $0(0 \%)$ & $0(0 \%)$ \\
\hline & Grand Total & $\mathbf{4 0}$ & $\mathbf{4 0}$ \\
\hline
\end{tabular}

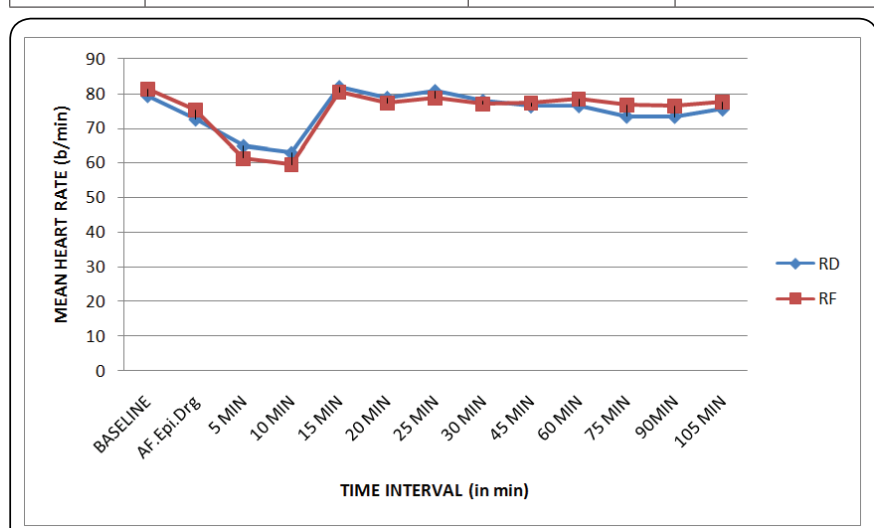

Figure 1: Mean Heart Rate.

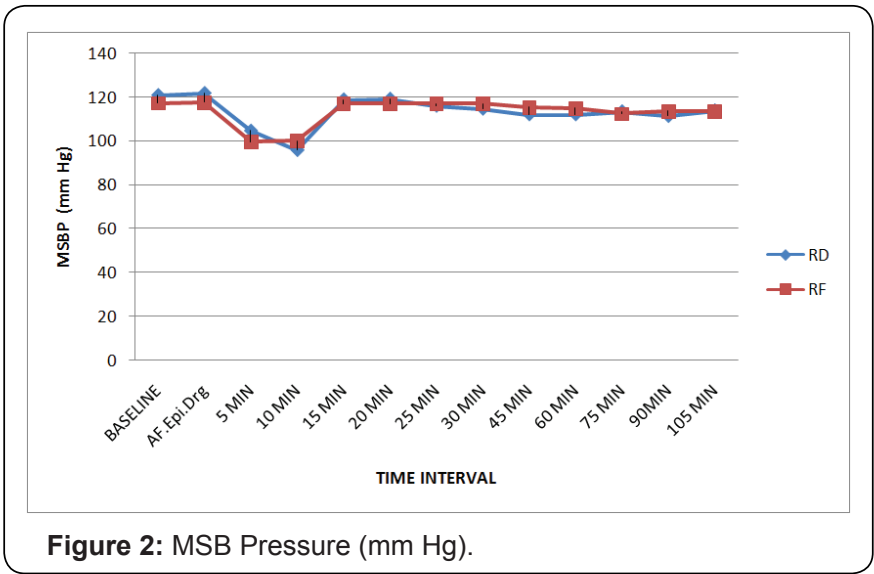

The fall in HR and mean SBPfrom baseline was significant at 5 min and 10 min interval after injecting epidural drug in both the Groups $(p<0.0001)$. But the change in HR and mean SBP was statistically comparable between two at various other time intervals (p>0.05) (Figure $1 \& 2$ ). The fall in mean DBP from the baseline was significant at $5 \mathrm{~min}, 10 \mathrm{~min}, 15 \mathrm{~min}, 20 \mathrm{~min}$ and $25 \mathrm{~min}$ in Group RD while it was significant at $15 \mathrm{~min}$ and 20 min in Group RF after injecting epidural drug ( $<<0.0001)$. But the change in DBP was statistically comparable between two Groups RD and RF at various other time intervals ( $\mathbf{p}>\mathbf{0 . 0 5})$. 
Figure 3 Mean $\mathrm{RR}$ and $\mathrm{SPO}_{2}$ was comparable in both the groupsRDand RF during our entire study period, respectively (p>0.05). Comparison between the groups showed statistically no significant difference in the complications/side effects $(p$ $>0.05$ ). Incidence of hypotension, bradycardia and dry mouth was significantly high in Group RD, while nauseaand vomiting was significantly high in Group RF ( $\mathrm{p}<0.05)$ (Table 4).

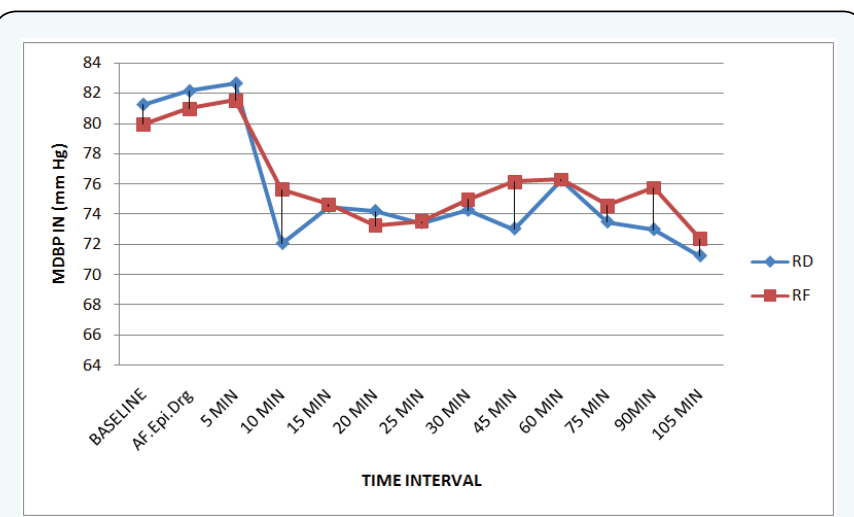

Figure 3: MDB Pressure.

Table 4: Incidence of Side Effects and Complications.

\begin{tabular}{|c|c|c|c|}
\hline S No. & Complication & RD & RF \\
\hline 1 & Nausea & $07(12.5 \%)$ & $16(40 \%)$ \\
\hline 2 & Vomiting & $02(5.0 \%)$ & $04(10 \%)$ \\
\hline 3 & Bradycardia & $10(25 \%)$ & $05(12.5 \%)$ \\
\hline 4 & Shivering & $01(2.5 \%)$ & $04(10.0 \%)$ \\
\hline 5 & Hypotension & $25(62.5 \%)$ & $12(30.0 \%)$ \\
\hline 6 & Dry Mouth & $10(25 \%)$ & $02(5 \%)$ \\
\hline 7 & Headache & $02(5.0 \%)$ & $1(2.5 \%)$ \\
\hline 8 & Urinary Retention & $00(0.0 \%)$ & $00(0.0 \%)$ \\
\hline 9 & Respiratory Depression & $00(0.0 \%)$ & $00(0.0 \%)$ \\
\hline
\end{tabular}

\section{Discussion}

The aim of this study is to evaluate and compare the efficacy of $0.75 \%$ ropivacaine and fentanyl with $0.75 \%$ ropivacaine and dexmedetomidine in epidural anaesthesia in patients undergoing lower abdominal surgeries.

I. The primary objective of this study is to compare the onset of sensory block between dexmedetomidine and fentanyl.

II. The secondary objective of this study is to compare the onset of motor blockade, extent of block, duration of sensory and motor block, duration of analgesia, sedation score, total LA consumption and occurrence of side effects in the intraoperative period between the two drugs.

In our study onset of sensoryand motor block was earlier in group RD as compared to group RF, and the difference was statistically highly significant $(\mathbf{p}<\mathbf{0 . 0 0 0 1})$. It correlated with findings of Vasupalli $\mathrm{R}$ et al. [6] and Agrawal S et al. [7]. The amount of study drug and adjuvants used in both the studies were similar to the amount of drugs used in our study.

Highest level of sensory block achieved was T5-T6 in group RD (34 patients) and T6-T7 in group RF (35 patients). This showed the block was higher in group RD in maximum number of patients compared to group RF. Similar results were observed in group RD as compared to group RF in Bajwa S, et al. [5] and in Vashisth, et al. [8] where highest level was T5 in group RD and T6 in group RF. The result of Bajwa S et al. [5] and Vashisth, et al. [8] was similar as the study and adjuvants dexmedetomidine, clonidine and fentanyl used was $1 \mu \mathrm{g} / \mathrm{kg}$ which is similar to our study.

Duration of sensory block wasprolonged in group RD compared to group RF andthe difference was statistically highly significant. $(\mathbf{p}<\mathbf{0 . 0 0 0 1})$ Similar results were seen in study of Bajwa SJ, et al. [9] when same amount of drug was given as in our study. Duration of motor block and duration of analgesia was also longer in group RD as compared to group RF, and the difference was also statistically highly significant $(\mathbf{p}<\mathbf{0 . 0 0 0 1})$. Similar results were seen in study of Singh R et al. [10] where duration of motor block was prolonged in group RD as compared to group RF and in Mittal AA et al. [3] where duration of analgesia was prolonged in group RD compared to group RF.

Total LA consumption was significantly lesser in group RD as compared to group RF.This was similarly seen in study of Mittal AA, et al. [3] and Baglur S, et al. [11], where dexmedetomidine was given in same dose as in our study proving dexmedetomidine a better alternative to fentanyl.

In our study maximum number of patients in both the groups had grade II sedation score and higher number of patients in group RD had grade III and grade II score as compared to group RF. This showed dexmedetomidine provided better sedation scores compared to fentanyl, similar results were shown in study of Singh R, et al. [12] where $36 \%$ and $46 \%$ patients had grade II and grade III sedations scores compared to $18 \%$ and $4 \%$ in patients of group RF.

Mean RR was comparable in both the Groups and was statistically insignificant throughout the surgical procedures (p>0.05). Mean RR was above 12/min in both the Groups throughout whole duration of procedure. $\mathrm{SpO}_{2}$ was above $95 \%$ in all the patients of Group RD and Group RF throughout the study period and the difference was statistically insignificant (p>0.05).

Significant decrease in mean HR and SBP from the baseline was observed in group RD and RF was observed after 5 min and 10 min of injecting study drug but was comparable after 10 mins to throughout the procedure, this correlated with the studies of Bajwa SJ, et al. [9] and Singh RB, et al. [12] as same adjuvant 
and study drug was used. The fall in mean DBP in group RD correlated with studies of Rastogi B et al. [13] and Singh RB, et al. [12] while in group RF correlated with Singh RB, et al. [12].

Incidence of nausea was higher and significant in Group RF as compared to Group RD and vomiting was slightly higher in Group RF as compared to Group RD. The findings of our study that fentanyl when used as adjuvant causes nausea and vomiting correlates with Singh RB, et al. [12] and Harinath G et al. The incidence of hypotension and bradycardia was higher in Group RD patients as compared to and patients in Group RF. The difference was comparable and stastically significant $(\mathrm{p}<0.05)$. The findings observed in Baglur S, et al. [11] and Singh RB, et al. [12]) that there was comparable difference in hypotension and bradycardia as clonidine was used, which is also an alpha 2 agonist, correlates with our study. The incidence of shivering in Group RD and Group RF was comparable and statistically not significant. (p>0.05) The incidence of dry mouth was statistically significantin Group RD as compared to in Group RF $(\mathrm{p}<0.05)$. The incidence of headache was not significant in both the groups while none of the patients had urinary retention in either Group ( $\mathbf{p}>\mathbf{0 . 0 5}$ ) (Table 3).

\section{Conclusion}

Our study shows faster onset, prolonged duration and excellent sensory and motor blockade along with better sedation, stable hemodynamics following epidurally administered dexmedetomidine with ropivacaine compared to fentanyl with ropivacaine. Thus it could be concluded that dexmedetomidine is better alternative to fentanyl as an adjuvant for epidural anaesthesia with ropivacaine for lower abdominal surgeries.

\section{References}

1. Kehlet H (1999) Acute pain control and accelerated postoperative surgical recovery. Surg Clin North Am 79(2): 431-443.

2. Schultz AM, Werba A, Ulbing S Gollmann G, Lehofer F (1997) Perioperative thoracic epidural analgesia for thoracotomy. Eur J Anaesthesiol 14(6): 600-603.
3. Mittal AA, Saxena A, Chand T, Agrawal A (2016) Role of Fentanyl Vs Dexmedetomidine as an Adjuvant to Ropivacaine in Epidural Anaesthesia for Infra-Umbilical Surgeries. IJSR 5(3): 305.

4. Soni P (2016) Comparative study for better adjuvant with ropivacaine in epidural anaesthesia. Anaesth essays Res 10(2): 218-222.

5. Bajwa SJ, Arora V, Kaur J, Singh A, Parmar SS (2011) Comparative evaluation of dexmedetomidine and fentanyl for epidural analgesia in lower limb orthopaedic surgeries. Saudi J Anaesth 5(4): 365.

6. Vasupalli R, Prakash TSN (2016) A comparative study of dexmedetomidine and fentanyl combined with ropivacaine for epidural anaesthesia in lower limb orthopaedic surgeries. J Evid Based Med Healthcare 3(71): 2349-2570.

7. Agrawal S, Gupta K, Gupta PK, Bansal M, Sharma R, Aqsa Buchh (2016) Clonidine versus fentanyl as adjuvant to $0.75 \%$ ropivacaine for epidural anaesthesia for lower limb surgeries: a comparative evaluation. Int Res Med Sci 4(8): 3606-3610.

8. Vashishth T, Verma M, Garg S, Sharma G, Vashishth S (2016) Comparative study of dexmedetomidine and fentanyl with ropivacaine $0.75 \%$ in epidural analgesia in lower limb orthopaedic surgeries. National Journal of Medical and Dental Research 4(3): 201-212.

9. Bajwa SJ, Bajwa SK, Kaur J, Gupta S, Arora V, et al. (2011) Dexmedetomidine and clonidine in epidural anaesthesia: A comparative evaluation. Indian J Anaesth 55(2): 116-121.

10. Singh R, Acharya G, Abhimanyu Rana, Arora KK, Kumar D, et al. (2016) Comparative Evaluation Of Addition Of Fentanyl And Dexmedetomidine To Ropivacaine For Epidural Anaesthesia and Analgesia In Lower Abdominal And Lower Limb Orthopaedic Surgeriese jpmr 3(2): 200205.

11. Baglur S, Dinesh K, Ravi M, Somasekheram (2015) A comparative study of epidural ropivacaine $0.75 \%$ alone with ropivacaine plus fentanyl and ropivacaine plus clonidine for lower abdominal and lower limb surgeries, IOSR Journal of Dental and Medical Sciences 14(12): 19-267.

12. Singh RB, Singh D, Mishra PK, Kumar M (2015) Epidural ropivacaine combined with fentanyl or in combination with clonidine in infraumbilical surgeries. Int J Res Med Sic 3(10): 2740-2744.

13. Rastogi B, Singh VP, Mangla D, Gupta K, Jain M (2015) Dexmedetomidine as an adjuvant to epidural $0.75 \%$ ropivacaine in patients undergoing infraumbilical surgery: a clinical study. Glob Anesth Perioper Med 1(1): 19-23.

\section{Your next submission with Juniper Publishers} will reach you the below assets

- Quality Editorial service

- Swift Peer Review

- Reprints availability

- E-prints Service

- Manuscript Podcast for convenient understanding

- Global attainment for your research

- Manuscript accessibility in different formats

( Pdf, E-pub, Full Text, Audio)

- Unceasing customer service

Track the below URL for one-step submission https://juniperpublishers.com/online-submission.php 